\title{
Rupture of the tympanic membrane following assault: a retrospective study of victims of violence who presented to the private sector
}

The tympanic membrane can rupture due to many causes (Table 1). The most common cause of rupture is assault over the ear squarely with the hand. This occurs frequently as a sequel to domestic violence. No study has been done to evaluate the nature or extent of the problem in this country. The purpose of this study was to assess the population characteristics of the victims of assault, their assailants and nature of the victims' otological manifestations.

Table 1. Causes of rupture of the tympanic membrane

Traumatic causes

Infective causes

Assault

Fracture base of skull Middle ear infection

Bomb blasts' External ear infection

Foreign bodies in the ear

Barotrauma

General anaesthesia

with nitrous oxide ${ }^{2}$

Lightening

Insertion of ventilation

tubes in children ${ }^{4}$

Data were collected from individuals who presented to the outpatient clinic of a private sector hospital. They presented to the surgeon 1 to 30 days after the assault. A total of 25 patients were assessed, and 23 patients $(92 \%)$ were females. They fell within an age range of 16 to 62 years.
A majority of the victims were housewives $(n=9)$. Of the 23 female victims 17 were assaulted by their husbands $(n=16)$. The only two male victims in the study, who were both students, were each assaulted by a fellow student. The other female victims in the study were assaulted by their relatives eg. the father, brother, son-in-law. The housemaid was assaulted by her employer. These details are summarised in Table 2 .

A majority of the assailants were males. Their ages were in the age range of 8 to 68 years. There was only one female assailant, an 8-year old child. Most victims were assaulted following a family disagreement $(n=21)$. Two female victims were injured following accidental striking of the ear by children aged 8 and 10 years.

Following assault a majority of the victims $(n=17)$, complained of tinnitus in the affected ear. The second common complaint was blocking of the ear $(n=14)$. The other presenting complaints in descending order of frequency were headache, deafness, pain in the ear and vomiting $(12 \%)$.

Twenty four patients had a perforated tympanic membrane and one patient did not have any visible damage to the ear drum. 12 patients had bilateral afflictions. The posterosuperior quadrant was most commonly affected, followed by the posteroinferior quadrant, anteroinferior quadrant and the anterosuperior quadrant. Larger perforations as well as those that involve the posterosuperior quadrant of the membrane gave rise to a more profound hearing impairment and took a greater time to heal (5). Although all patients were requested to present themselves for follow up 2 weeks after the initial consulation only 7 did so.

Table 2. Occupations of the victims and their assailants

Victims

Housewife

Clerk

Student

Banker

Housemaid

Teacher

Garment worker

Computer operator
Assailants

Businessman
Office peon
Student
Child
Police officer
Private security officer
Banker
Retired government servant
Unemployed

Relationship between female victims and their assailant

Husband
Other relative
Father
Brother
Son-in-law
Employer


Most victims sustained tympanic membrane rupture as a consequence of domestic violence, and a majority of the victims were females. The presence of a ruptured tympanic membrane in a female patient in the absence of a history of assault should alert the clinician to the possibility of physical abuse in a domestic setting.

\section{References}

1. Pahor AL. The ENT problems following Birmingham bombings. Journal of Laryngology and Otology 1981; 95: 399-406.
2. Vones DT, Orgen FP, Roh LH, Moor GF. Lightening and its effects on the auditory system. Laryngoscope 1991; 101:830-4.

3. Oluwole M, Mills RP. Tympanic membrane perforation in children. International Journal of Paediatrtic Otolaryngology 1996; 36: 117-3.

4. Kristensen S. Spontaneous healing of traumatic tympanic membrane perforation in man: a century of experience. Journal of Laryngology and Otology 1992; 106: 1037-9.

5. Weber PC, Klein AJ. Hearing loss. Surgical Clinics of North America 1999; 83: 129-42.

Asoka Jayasena, ENT surgeon and D A Niriella, Registrar in otorhinolaryngology, Sri Jayawardenepura General Hospital, Thalapathpitiya. (Accepted 19 September 2001) 